HID 45 (2018)

\title{
EL CABILDO MALLORQUÍN EN LA ÉPOCA DE LA ILUSTRACIÓN (1750-1800) ${ }^{1}$
}

\author{
THE CATHEDRAL CHAPTER OF MAJORCA DURING THE AGE OF \\ ENLIGHTENMENT (1750-1800)
}

\author{
Francisco José García PÉREZ ${ }^{2}$ \\ Universitat de les Illes Balears-IEHM \\ fj.garcia@uib.es ORCID: https://orcid.org/0000-0002-9459-3550
}

RESUMEN: Este artículo persigue el estudio del Cabildo catedralicio de Mallorca durante la segunda mitad del siglo XVIII. En estas líneas, se analizará la jerarquía del Cabildo, las formas de acceder a las prebendas y la extracción social de sus miembros. Pero especialmente, se estudiará la evolución del clero capitular de Mallorca durante las grandes reformas ilustradas implantadas por Carlos III, que se tradujeron en importantísimos cambios y transformaciones para dicha institución.

PalabRas ClaVE: Cabildo; Mallorca; Obispo; Lulismo.

ABSTRACT: This article pursues the study of the Cathedral Chapter of Mallorca during the second half of the $18^{\text {th }}$ century. In these lines, its hierarchy, the ways to access the prebends and the social extraction of its members will be analysed. But especially, the evolution of the cathedral clergy of Majorca will be studied during the great Enlightenment reforms implanted by Carlos III, which resulted in very important changes and transformations for this institution.

KeYwORDS: Cathedral Chapter; Majorca; Bishop; Lullism.

Recibido: 10-1-2018; Aceptado: 19-3-2018; Versión definitiva: 21-3-2018.

1. Este artículo se ha realizado en el marco de una beca posdoctoral "Margalida Comas" concedida por el Govern de les Illes Balears y cofinanciada por el Fondo Social Europeo a través del Programa Operativo del FSE de las Illes Balears para el período 2014-2020.

2. Abreviaturas utilizadas: ACM (Arxiu Capitular de Mallorca), ARM (Arxiu del Regne de Mallorca), AMP (Arxiu Municipal de Palma), BBM (Biblioteca Bartomeu March), AHN (Archivo Histórico Nacional).

Copyright: (C) Editorial Universidad de Sevilla. Este es un artículo de acceso abierto distribuido bajo los términos de la licencia de uso y distribución Creative Commons Reconocimiento-No-ComercialSinObraDerivada 4.0 (CC BY-NC-ND 4.0) 
Actualmente asistimos a una floreciente época para el estudio de las élites eclesiásticas de la Edad Moderna. Tomando como referente las investigaciones de Díaz Rodríguez ${ }^{3}$, son tantos los historiadores e historiadoras interesados en esta temática, que se está dibujando un verdadero mosaico de estudios sobre cabildos en la España Moderna. Incluso podría pensarse que una institución tan compleja como es el Cabildo catedralicio está de moda. En lo que al Cabildo de Mallorca se refiere, la historiografía isleña ha desatendido su estudio durante mucho tiempo. Aunque es cierto que recientemente han salido a la luz algunas contribuciones, todavía son muchos los ámbitos del Cabildo pendientes de análisis ${ }^{4}$. Partiendo de esta premisa, este artículo pretende estudiar un período en la historia del Cabildo de Mallorca que tuvo serias repercusiones de cara a la institución capitular. Tras la subida al trono de Carlos III, se experimentaron vivos proyectos de reforma que afectaron también a las catedrales hispánicas. Mientras se reforzaba la autoridad de los obispos, se revivía el espíritu de Trento y se purgaban excesos y desmanes demasiado enquistados en la Iglesia española, los canónigos de Mallorca -al igual que muchos de sus homólogos peninsulares- vieron mermar su antaño incuestionado ascendiente social y religioso. Por supuesto, este reformismo borbónico también afectó al funcionamiento del clero capitular. Ámbitos como la provisión de las prebendas o su misma jurisdicción sufrieron algunas modificaciones.

Las fuentes para el estudio del Cabildo no son muy variadas, pero lo cierto es que sí ofrecen datos realmente interesantes. En lo que respecta a este artículo, la principal fuente documental es el libro donde se recoge la nómina completa de las dignidades y canonjías de la Catedral, contando con las pavordías del coro, o también llamadas canonjías de gracia, que formaban parte del Cabildo, aunque solo tuviesen un papel simbólico, como veremos. Conservado en el Archivo Capitular de Mallorca (ACM), este libro contiene información de todos los miembros que se sucedieron en las prebendas a lo largo de la Edad Moderna, así como sus vías de acceso. Junto a este documento de gran interés, contamos también con las actas capitulares, que recogen información muy variada.

Pero, además, las crecientes disputas que se vivieron entre canónigos y obispos, especialmente en un momento de enormes cambios y reformas, obligaron a la Corona a intervenir. De modo que también es de especial interés documentación perteneciente al Archivo Histórico Nacional (AHN), concretamente las deliberaciones que se tomaron en el Consejo de Castilla.

3. Véase Díaz Rodríguez 2012.

4. Ayreflor Sureda 1947; Rosselló Lliteras 1980; Alcina 1985; Xamena y Riera 1986, pp. 173175; Montaner 1990, p. 83; Amengual i Batle 2002, pp. 101-104; Barceló Crespí y Ensenyat Pujol 2014; García Pérez 2014a, 2014 b, 2017a, 2017 b. 


\section{JERARQUía Y ORGANIZACIÓN DEL CABILDO: CAMBIOS Y CONTINUIDADES}

Como todos los cabildos, el de Mallorca se regía también por una organización interna que venía postergándose prácticamente sin modificaciones desde hacía siglos. Dividido entre canónigos y beneficiados, el Cabildo mallorquín contaba con un total de veintidós canonjías, y así fue hasta el Concordato de 1851. El máximo escalafón jerárquico lo ocupaban las cinco dignidades: deán, arcediano, chantre, sacristán y tesorero ${ }^{5}$. Por regla general, quienes portaban esta dignidad eran ya canónigos propiamente y sus funciones afectaban a todos los recodos de la vida capitular ${ }^{6}$. Mientras el deán sujetaba las riendas del gobierno sobre todos los miembros de la $\mathrm{Seo}^{7}$, el arcediano funcionaba como una especie de alter ego del anterior y se había convertido en una figura más bien simbólica ${ }^{8}$. Asimismo, el sacristán supervisaba la preparación del ceremonial litúrgico y velaba por el cuidado de la sacristía capitular, uno de los espacios con mayor simbología de la Catedral ${ }^{9}$. El tesorero se ocupaba de la reparación y reposición del tesoro y las reliquias catedralicios. Y, finalmente, la dignidad de chantre tenía bajo su jurisdicción otro de los espacios más importantes: el coro ${ }^{10}$. De hecho, el chantre se encargaba precisamente de dirigir la buena marcha de los oficios religiosos, así como del mantenimiento de los mozos del coro.

La mayoría de las catedrales tenían dotadas cuatro canonjías de oficio. A diferencia del resto de prebendas, estas se cubrían mediante un concurso oposición y tenían unas funciones inherentes que sus posesores debían cumplir. Los requisitos que se exigían a los aspirantes variaban en función de la canonjía. De modo que estas cuatro canonjías suponían una de las renovaciones tridentinas más significativas en los cabildos, pues, en palabras de Rey Castelao, introducían la cualificación intelectual en un ámbito en el que el reclutamiento se hacía por la vía de influencia familiar y clientelar ${ }^{11}$.

Primeramente, el canónigo penitenciario ejercía la asistencia espiritual de los miembros de la Catedral. A su vez, el lectoral, como su nombre indica, se reservaba la lectura de las Sagradas Escrituras durante el oficio de la misa; el magistral era el encargado de predicar los sermones; $y$, finalmente, el doctoral era el asesor jurídico del Cabildo. Sin embargo, en una fecha tan tardía como 1750, la Catedral mallorquina únicamente contaba con dos de las cuatro canonjías de oficio. La penitenciaria había sido dotada ya en el siglo XVII, y durante mucho tiempo funcionó mediante las vías patrimonializadoras tan típicas del clero capitular ${ }^{12}$. En

5. Para un análisis de las principales fuentes de consulta que ayudan a conocer mejor las dignidades y canonjías de una catedral véase Burón Castro 2006, pp. 209-225.

6. Rosselló Lliteras 1980, p. 194.

7. Beltrán Almozán y Toledano Galera 1988, p. 39.

8. García Pérez 2017b, p. 411.

9. Fernández Gracia 1999, p. 349.

10. Escámez Mañas 2015, p. 97.

11. Rey Castelao 1998, p. 350.

12. Barrio Gozalo 2010b, 52. 
cuanto a la lectoral, fue introducida en el Cabildo en 1713, siendo asumida por el entonces deán Don Joan Martorell ${ }^{13}$.

Hubo que esperar muchos años para constatar nuevos atisbos de reforma dentro de la Catedral. Primeramente, la firma del Concordato de 1753 entre Fernando VI y la Santa Sede contribuyó, en gran medida, a erradicar las tan enquistadas políticas de patrimonialización de las prebendas, limitando en exceso el abusivo uso de la coadjutoría y la resigna ${ }^{14}$. Asimismo, se terminó con una práctica que había sido una tónica muy habitual a lo largo del siglo XVII: la acumulación de prebendas por un mismo individuo ${ }^{15}$. Tras verse promocionados, algunos canónigos no cedían sus prebendas hasta conseguir que se sucediese en ellas un candidato óptimo. Y si bien, esta práctica había caído prácticamente en desuso a inicios del siglo XVIII, tras la firma del Concordato ya no se constataron más casos.

Por otro lado, bajo el reinado de Carlos III, el creciente intervencionismo de la Corona en asuntos eclesiásticos y los intentos del episcopado español por implantar reformas encaminadas a revivir el espíritu de Trento y mejorar el estado de las diócesis, también tuvieron su repercusión en el Cabildo. En 1770, el obispo Francisco Garrido de la Vega (1763-1772) consideró como necesario dotar a la Catedral de las dos canonjías de oficio que todavía le faltaban ${ }^{16}$. Así que ese mismo año se convocó el concurso oposición. El primer canónigo doctoral fue el Dr. Antoni Bisquerra, catedrático de Instituta en la Universidad Luliana de Mallorca ${ }^{17}$, y la canonjía magistral recayó en el Dr. Antoni Nicolau Lobo, que por aquel entonces era pavorde del coro, y pasó a ser canónigo de facto ${ }^{18}$.

En el Cabildo mallorquín, la jerarquía marcaba el día a día en las relaciones de sus miembros. Cada cual sabía perfectamente a quién debía ceder el paso y por delante de quién tenía preferencia en los servicios religiosos, reuniones capitulares y asistencia al coro. Primeramente, y a diferencia de otras catedrales en las que la antigüedad marcaba el orden de precedencia, en la mallorquina, las canonjías se dividían en función de si eran presbiterales, diaconales y subdiaconales. Finalmente, en el escalón inferior, el Cabildo mallorquín contaba con cuatro canonjías de gracia reservadas a los pavordes del coro del obispo y del arcediano. Estos pavordes vestían igual que el resto de canónigos, pero no tenían voto ni acceso a las reuniones capitulares. Únicamente ejercían de representantes del obispo y del arcediano cuando el Cabildo se reunía en el coro y los dos anteriores no se hallaban presentes. La función de estas cuatro pavordías era, principalmente, servir de trampolín para entrar en el universo capitular y aspirar, desde allí, a una canonjía ${ }^{19}$. Esto explica mejor el hecho de que sus poseedores por lo general lo fueran duran-

13. El primer canónigo lectoral fue don Joan Martorell, deán de la Catedral desde 1695. Martorell asumió dicha canonjía en virtud del decreto de la Sagrada Congregación de Ritos, del 26 de agosto de 1713 y la resolución capitular del 18 de abril de 1714. ACM, Actas Capitulares, ACA, 1643, f. 39r.

14. Díaz Rodríguez 2012, p. 261.

15. García Pérez 2017a, p. 417.

16. ACM, Actas Capitulares, ACA 1658, f. 38v.

17. Planas Rosselló y Ramis Barceló 2011, p. 83.

18. Cassanyes Roig y Ramis Barceló 2015, p. 101.

19. García Pérez 2014a [versión electrónica]. 
te poco tiempo, aprovechando cualquier oportunidad de promoción para escalar dentro del Cabildo. Únicamente destaca una excepción reseñable, y es la de Don Guillem Terrassa ${ }^{20}$, famoso cronista, que se convirtió en pavorde en 1701 y lo fue hasta su muerte en $1778^{21}$.

La pertenencia al clero capitular se traducía, por lo general, en una carrera que duraba toda la vida. De hecho, gran número de canónigos tuvo que pasar por los distintos escalones jerárquicos de la Catedral hasta llegar a lo más alto. De modo que la mayoría de las veces se trataba de un cursus honorum interno que no trascendía más allá del universo capitular, con la excepción reseñable de aquellos canónigos que eran promocionados a un obispado. Unas veces, si el aspirante contaba con una familia ilustre que lo protegiese, o incluso que ya formaba parte del Cabildo, podía entrar directamente en él sucediéndose en una canonjía. Ese fue, por ejemplo, el caso de Don Ramon Despuig i Fortuny, que ingresó directamente como sochantre -asistente en funciones del chantre- cuando su hermano mayor renunció en su favor ${ }^{22}$. En 1751, su primo, el obispo Llorenç Despuig, le promocionó a chantre de la Catedral. Sin embargo, otros canónigos lo tuvieron más difícil para hacerse un sitio en aquel reducto donde la influencia social y el poder eran dos bazas indispensables. Por ejemplo, el Dr. Don Antoni Nicolau Lobo consiguió acceder al Cabildo a través de una de las pavordías del coro en 1751. Veinte años después vio su oportunidad cuando el obispo Garrido de la Vega convocó oposiciones para las canonjías de oficio que aún faltaban. Finalmente, Lobo se convirtió en canónigo magistral de la Catedral hasta su muerte en $1807^{23}$.

\section{FormAS DE ACCESO AL CLERO CAPITULAR ¿EL FINAL DE LA PATRIMO- NIALIZACIÓN DE LAS PREBENDAS?}

A lo largo de la Edad Moderna hubo distintas formas de provisión de las prebendas capitulares. Durante el Concilio de Trento se habían perfilado los criterios y normas de elección ${ }^{24}$. Dependiendo del mes en el que vacaba la canonjía, su

20. Guillem Terrassa escribió a lo largo de su vida los Anales del Reino de Mallorca donde recopilaba una enorme cantidad de noticias históricas, con especial incidencia en los acontecimientos que vivió hasta su muerte en 1780. Además, escribió otras obras de enorme interés histórico, y que todavía son de gran utilidad para conocer de primera mano la historia eclesiástica de Mallorca, especialmente en el siglo XVIII. Véase Terrassa 1883.

21. ACM, Libro de posesorios de las dignidades canónicas, sucentoría y pavordías de esta Santa Iglesia, núm. 15.576, f. 91r.

22. ACM, Libro de posesorios de las dignidades canónicas, sucentoría y pavordías de esta Santa Iglesia, núm. 15.576, f. 82v.

23. ACM, Actas Capitulares, ACA 1658, f. 38v.

24. Maximiliano Barrio Gozalo perfila los criterios básicos de los candidatos a una prebenda capitular: "las dignidades que tenían cura de almas sólo podían conferirse a quienes hubieran cumplido veinticinco años, estuvieran ordenados in sacris y tuvieran formación y ciencia que requería el recto cumplimiento de su oficio, y sus costumbres fueran de una integridad probada". A esto se le sumaba un idóneo bagaje cultural que se traducía en la posesión de un grado universitario, así como un linaje familiar exento de todo nexo con conversos o castigados por la Inquisición. Barrio Gozalo 2010b, p. 102. 
provisión recaía directamente en la Santa Sede o en cabildos y obispos. Sin embargo, la realidad a menudo solía ser muy distinta. Eran muchos los intereses que despertaban las prebendas capitulares, especialmente para los estamentos más poderosos. De forma ininterrumpida, en el transcurso de los Siglos Modernos, la nobleza y algunas de las familias más poderosas y enriquecidas de Mallorca habían ambicionado colocar a sus vástagos en el Cabildo, institución que gozaba de un enorme prestigio social, capitaneaba la cúspide eclesiástica junto con los obispos y permitía a sus miembros disfrutar de unos réditos económicos nada desdeñables ${ }^{25}$. Por eso mismo, la provisión de las prebendas no se reducía, ni mucho menos, a lo anterior. Todo lo contrario, había otros mecanismos que se traducían en una descarada estrategia de patrimonialización, de tal modo que familiares, clientes y amigos se sucediesen en las prebendas, quedando estas en poder de un clan o familia ${ }^{26}$.

La primera de estas vías de provisión era la coadjutoría ${ }^{27}$. Cuando un canónigo se hallaba enfermo o demasiado mayor como para continuar ejerciendo las funciones capitulares, elegía a un aspirante - la mayoría de las veces un familiary solo tenía que presentar su candidatura a la Santa Sede, que despachaba las bulas oportunas. El coadjutor era ya miembro del Cabildo y, entre sus funciones y privilegios, actuaba como si del principal se tratase, asumiendo sus deberes y responsabilidades, pero siempre sin ningún poder de decisión sobre el destino del beneficio $^{28}$. Eso sí, la mayoría de las veces se sucedía en la prebenda cuando el titular moría. Por tanto, mediante la coadjutoría, el canónigo conseguía un doble fin: asegurarse un futuro cómodo, a la vez que introducía a un candidato elegido por él en la Catedral, tejiéndose así auténticas dinastías familiares ${ }^{29}$.

Junto a esta, otra de las vías de provisión preferidas era la resigna, que pese a buscar los mismos fines que la anterior, tenía características distintas. Se trataba de una especie de dimisión, pero en la que el dimisionario elegía al que iba a ser su sucesor ${ }^{30}$. De modo que, cuando un canónigo abandonaba una prebenda, se aseguraba de que se sucediese en ella un candidato concreto, lo cual casaba perfectamente con las prácticas de clientelismo tan características de la Edad Moderna y la promoción de familiares en la escala social ${ }^{31}$.

La coadjutoría fue muy utilizada durante la primera mitad del Setecientos. Cuanto más importante era la prebenda, más común era su uso, principalmente porque el titular no pretendía ya continuar escalando y deseaba disfrutar de los réditos económicos que recibía, pero delegando sus funciones a alguien más joven y asegurando a la vez el destino de un familiar o cliente ${ }^{32}$. Por otro lado, la resigna fue más común en los escalones inferiores del Cabildo, principalmente porque aquellos que se valían de ella, lo hacían porque eran promocionados, pero

25. Amengual i Batle 2002, p. 102

26. Iglesias Ortega 2016, p. 265.

27. Díaz Rodríguez 2009, p. 287.

28. Irigoyen López 2001, p. 50.

29. Morgado García 1997, p. 229.

30. Latorre Ciria 2009, p. 559.

31. Díaz Rodríguez y López-Salazar Codes 2014, p. 45.

32. García Pérez 2014a. 
deseaban primero reforzar sus lazos familiares. De hecho, su uso se hizo verdaderamente extensible a las pavordías del coro, ya que suponían la llave de entrada al Cabildo y la vía para continuar escalando hacia las tan ansiadas canonjías. Sin embargo, durante la segunda mitad del siglo XVIII se dieron importantes cambios que parecían romper con siglos de tradición. Mientras en los primeros cincuenta años de la centuria se constató el uso de la coadjutoría en veintisiete ocasiones y de la resigna en ocho, a partir de 1753 su número descendió estrepitosamente. Únicamente se dieron cuatro casos de coadjutoría y dos de resigna, todos ellos concentrados entre 1751 y $1761^{33}$. A partir de esa fecha no vuelven a utilizarse dichas prácticas.

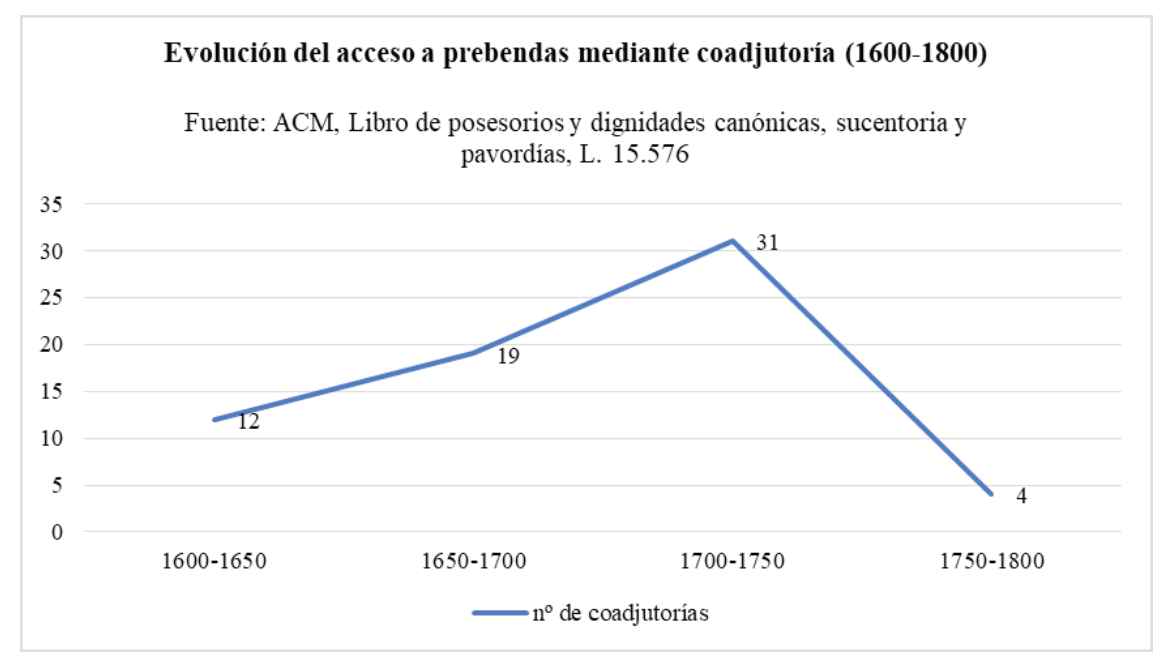

Como puede comprobarse en la gráfica anterior, el uso de la coadjutoría estaba plenamente extendido dentro del Cabildo. A lo largo del siglo XVII, los casos de coadjutorías fueron aumentando, siempre de cara a una visión patrimonializadora de las prebendas ${ }^{34}$. Durante la primera mitad del XVIII, la situación llegó a tales niveles, que fueron muchos los obispos que denunciaron sin éxito el excesivo uso de estas prácticas por parte del clero capitular. Felipe $\mathrm{V}$ se vio finalmente forzado a cercenar drásticamente la utilización de la coadjutoría mediante un Real Decreto de $1745^{35}$. Sin embargo, todo indica que fue tras la firma del Concordato de 1753 entre la Santa Sede y Fernando VI, cuando se dieron por concluidas unas dinámicas que venían postergándose desde hacía siglos. A partir de entonces, se constata,

33. Los dos casos de resigna se dieron en la dignidad de chantre con el objetivo claro de que se mantuviese en ella un miembro de la familia y clientes de los Despuig. ACM, Libro de posesorios de las dignidades canónicas, sucentoría y pavordías de esta Santa Iglesia, núm. 15.576, f. 12r.

34. García Pérez, 2017b, p. 416.

35. Díaz Rodríguez 2004, p. 261. 
primeramente, un desuso progresivo pero firme de la utilización de coadjutorías y resignas. Y, en segundo lugar, se observa un aumento considerable del intervencionismo regio y episcopal en la provisión de prebendas.

Esta intromisión no era un fenómeno privativo del siglo XVIII. Todo lo contrario, el Cabildo de Mallorca contaba con una canonjía reservada siempre a la provisión real y distintos obispos habían hecho promociones motivados por distintos intereses ${ }^{36}$. Unas veces, deseaban recompensar los servicios prestados. Otras colocar a hombres con los que poder trazar alianzas y políticas de colaboración, como ocurrió con Don Joan Martorell, vicario general del obispo Pedro de Alagón, que fue promocionado a deán por el prelado en $1695^{37}$. Y otras, se trataba de promover a clientes y familiares ${ }^{38}$, con el caso paradigmático del obispo Llorenç Despuig i Cotoner (1751-1763). Mallorquín de origen, Despuig se convirtió en prelado de Mallorca en 1751 y nada más llegar a su nueva diócesis, promocionó a sus dos primos, Joan y Ramon Despuig i Fortuny a las dignidades de deán y chantre respectivamente ${ }^{39}$. Sin embargo, es a partir del Concordato cuando se constata una infiltración todavía más exagerada por ambos poderes.

Por un lado, los obispos del reinado de Carlos III intentaron imponer su autoridad sobre el beligerante Cabildo, llegando a cotas muy arriesgadas. Y una forma de mantener intacto su poder dentro de la Seo fue mediante la promoción de aliados. A finales del siglo XVIII, el obispo Pedro Rubio-Benedicto y Herrero (17781794), uno de los grandes impulsores de las políticas ilustradas de Carlos III, volvió a promocionar nuevos miembros en el Cabildo, práctica que había caído en desuso por sus dos antecesores en la mitra ${ }^{40}$. Y si este medio no servía para domeñar al clero capitular, el creciente autoritarismo del que se vieron revestidos los prelados gracias al firme apoyo que les brindaba la monarquía carolina, supo hacer el resto, como se verá posteriormente ${ }^{41}$.

Pero si hubo una vía que experimentó un crecimiento desbordante en comparación con los siglos precedentes, fue la provisión de canonjías por el monarca. Si existía ya una canonjía diaconal reservada a la Corona, durante los reinados de Carlos III y Carlos IV, el intervencionismo regio ya no fue marginal. Teniendo presente que, tras el Concordato, el papa cedió el derecho al rey de España de nombrar y presentar candidatos a prebendas de las iglesias catedrales que vacasen en los ocho meses apostólicos, quedando los cuatro meses restantes reservados al obispo y el papado, es notable observar la desbordante influencia que pasaba a

36. Díaz Rodríguez 2012, p. 78.

37. ACM, Libro de posesorios de las dignidades canónicas, sucentoría y pavordías de esta Santa Iglesia, núm. 15.576, f. $7 \mathrm{v}$.

38. Para conocer un caso claro de políticas de nepostismo por parte de los arzobispos de Santiago de Compostela, véase Iglesias Ortega 2016, p. 261.

39. García Pérez 2014a.

40. ACM, Libro de posesorios de las dignidades canónicas, sucentoría y pavordías de esta Santa Iglesia, núm. 15.576, f. 94r.

41. García Pérez 2014b, p. 404. 
ejercer la Corona en las catedrales españolas. De tal modo que la abrumadora mayoría de provisiones a prebendas capitulares pasará ya por la Cámara de Castilla ${ }^{42}$.

La pregunta que inevitablemente se desprende es si tras el Concordato de 1753 se dio el final de siglos de patrimonialización de las prebendas capitulares. Los datos muestran que el uso de prácticas como la coadjutoría y la resigna terminaron en desuso durante el reinado de Carlos III. Sin embargo, esto no quiere decir que la influencia de las grandes familias nobiliarias, obsesionadas con mantener sus cotas de poder en todos los ámbitos de la vida social, hubiera terminado. Así como los Togores consiguieron monopolizar el acceso a la dignidad de sacristán durante la primera mitad de la centuria sin valerse de la coadjutoría ${ }^{43}$, otras estirpes mallorquinas siguieron su ejemplo, a pesar de las amplias limitaciones que había ocasionado el Concordato. Por ejemplo, la familia de los Despuig se perpetuó en la dignidad de chantre durante el resto del siglo XVIII. En 1758, Ramon Despuig i Fortuny renunció a la dignidad mediante la resigna y presentó a Joan Despuig i Despuig como nuevo candidato a la Santa Sede. Aquel hizo lo mismo en 1761 con su hermano, Llorenç Despuig i Despuig. Finalmente, el futuro cardenal, Antonio Despuig i Dameto, se convirtió en chantre tras la muerte del anterior en $1786^{44}$.

\section{Sociología de los CANÓNIGOS DEL CABILDO}

Durante toda la Edad Moderna, los cabildos catedralicios fueron centros de gran poder e influencia social. Al margen de la riqueza o pobreza inherentes a la misma institución, ser canónigo era, sin lugar a dudas, una meta muy codiciada. De hecho, y siguiendo a Díaz Rodríguez, ser prebendado era un objetivo en si mismo, una carrera autoconclusiva ${ }^{45}$. El caso mallorquín es todavía más paradigmático. La insularidad tuvo una consecuencia importantísima en su Cabildo. Primeramente, la transitoriedad de los obispos y su más que frecuente procedencia castellana durante el Setecientos reforzaba todavía más la idea colectiva del Cabildo como un poder permanente ${ }^{46}$. De hecho, uno de los momentos de mayor peso religioso se producía durante los períodos de sede vacante, tras el traslado o muerte del prelado, en que por la decidida pasión del Cabildo de aquella Catedral [de Mallorca], de cuyo gremio se elige el vicario capitular por ser todos los Prebendados naturales de aquel Reino ${ }^{47}$. En ocasiones, los canónigos habían sabido aprovechar este período de absentismo diocesano para revertir políticas incómodas, impopulares o que atentaban contra sus privilegios ${ }^{48}$.

42. Morgado García 1990, p. 345.

43. ACM, Libro de posesorios de las dignidades canónicas, sucentoría y pavordías de esta Santa Iglesia, núm. 15.576, f. 4v.

44. ACM, Libro de posesorios de las dignidades canónicas, sucentoría y pavordías de esta Santa Iglesia, núm. 15.576, f. 12r.

45. Díaz Rodríguez 2012, p. 127.

46. Amengual i Batle 2002, p. 103.

47. AHN, Consejos, L. 1948, f. 216r.

48. Véase García Pérez, 2017a. 
Por tanto, para sus miembros, el Cabildo suponía el máximo escalón de la jerarquía eclesiástica de la diócesis por debajo del obispo y, en consecuencia, la principal manera de abandonar el cuerpo capitular era convirtiéndose en prelados o ya falleciendo. En lo que respecta al primer caso, muy pocos prebendados obtuvieron una mitra episcopal. En concreto cuatro canónigos fueron promocionados a obispos por la Corona. Además, lo fueron de diócesis que pertenecían a los antiguos territorios de la Corona de Aragón ${ }^{49}$. Dos de ellos fueron promocionados a obispos de Mallorca, lo cual suponía una rara excepción. El primero fue Llorenç Despuig i Cotoner (1751-1763), hijo de los condes de Montenegro y canónigo de la Catedral desde 1728. El segundo, Bernat Nadal (1795-1818), proveniente de una familia humilde, entró en el Cabildo en 1787 tras una esmerada carrera académica $^{50}$.

Durante los Siglos Modernos, los cabildos estuvieron ampliamente dominados por los hijos de la nobleza ${ }^{51}$. Las familias mallorquinas pertenecientes al brazo noble aspiraban a mantener a uno de sus miembros dentro del cuerpo capitular, lo cual no solo les reportaba un enorme prestigio familiar, sino que también suponía infiltrar su mano dentro de una de las instituciones religiosas más poderosas de la diócesis de Mallorca $^{52}$. La descarada utilización de la coadjutoría y la resigna hasta la firma del Concordato de 1753 únicamente refuerza esta idea, y de hecho pueden localizarse los nombres de algunas de las estirpes nobiliarias más representativas, que por aquel entonces aglutinaban las llamadas Nou Cases. Como medio para acabar con décadas de discordias nobiliarias y banderías, en 1727, el capitán general de aquel momento, el marqués de Casafuerte, había forzado la unión de las familias nobiliarias más importantes de la isla a través de un pacto denominado precisamente Les Nou Cases, que potenciaba políticas endogámicas basadas principalmente en matrimonios ${ }^{53}$. Los apellidos de estas familias se localizan fácilmente dentro del Cabildo mallorquín, como es el caso de los Togores, que monopolizaron la dignidad de sacristán hasta $1792^{54}$.

Durante muchísimos años, hubo un elemento que permitía localizar muy fácilmente a estas familias, y era el uso del Don. Bajo los Austrias, el Don delimitaba perfectamente a la alta aristocracia mallorquina y solo los nobles propiamente

49. Llorenç Despuig i Cotoner fue nombrado obispo de Mallorca en 1751. Algunas de sus políticas no fueron bien vistas por Carlos III, por lo que fue trasladado a la archidiócesis de Tarragona en 1763. Quizás este fue el motivo por el que no volvió a haber provisiones episcopales por parte de canónigos mallorquines hasta el reinado de Carlos IV. En 1791 el cardenal Antonio Despuig i Dameto se convirtió en obispo de Orihuela, al año siguiente Bernat Nadal fue promovido a obispo de Mallorca y el menorquín Antonio Vila i Camps se convirtió en obispo de Menorca en 1798 tras la separación de dicha diócesis de la de Mallorca. ACM, Libro de posesorios de las dignidades canónicas, sucentoría y pavordías de esta Santa Iglesia, núm. 15.576, ff. 19r-25r.

50. Xamena y Riera 1986, p. 265.

51. Morgado García 2000, p. 85.

52. García Pérez 2014.

53. Morey Tous 1997, p. 61.

54. ACM, Libro de posesorios de las dignidades canónicas, sucentoría y pavordías de esta Santa Iglesia, núm. 15.576 , f. 4v. 
dichos lo usaban ${ }^{55}$. Sin embargo, durante la segunda mitad del siglo XVII, es decir bajo los reinados de Felipe IV y Carlos II, y coincidiendo también con la concesión de títulos a la nobleza mallorquina ${ }^{56}$, el uso del Don comenzó a hacerse extensible a la mayoría de dignidades y canónigos. Y si en la primera mitad del Setecientos, el $80 \%$ de los canónigos de la Catedral ya lo portaban, durante los siguientes cincuenta años de siglo nos encontramos con que el $99 \%$ de canónigos utilizarán el Don como propio. El uso del Magnífic, tan característico del estamento de cavallers - por debajo de la nobleza propiamente dicha en la jerarquía social- ya no vuelve a constatarse ${ }^{57}$.

Aunque se dio un predominio de presencia noble en el Cabildo, existían también otras vías de acceso a las prebendas capitulares para los integrantes del denominado brazo real. Autores como Pere de Montaner han localizado la presencia de ricos mercaderes infiltrados en el Cabildo ${ }^{58}$. Se trataba de canónigos sin una ascendencia social tan ilustre, pero que compensaban esas carencias mediante $l a$ preeminencia, rango y fastuosidad con que podían las mismas [familias] vivir, debido ciertamente a los beneficios que sus negocios mercantiles les habian proporcionado $^{59}$. El peso de estas familias aumentó enormemente en todas las instituciones políticas y religiosas mallorquinas conforme avanzaba la centuria, pues nos encontramos con hijos de estas familias enriquecidas no solo en el Cabildo, sino también como regidores del mismo Ayuntamiento de Palma. Además, había otra forma de ingresar en el Cabildo catedralicio y era portando un grado universitario $^{60}$. Los estatutos de Trento ya demandaban que, por lo menos, la mitad de los miembros del Cabildo fuesen graduados de maestro, doctor o licenciado en teología o derecho canónico ${ }^{61}$. Sin embargo, durante el siglo XVII, la inexistencia de una plataforma académica propia y el mismo fenómeno de insularidad de la diócesis mallorquina dificultaban enormemente esta circunstancia.

Hasta 1696, el Estudio General de Mallorca no pudo convertirse en Universidad propiamente y el Seminario conciliar, fundado en 1700, fue durante muchos años un proyecto decadente, que no terminaba de convertirse en aquello que Trento había demandado para la correcta formación del clero católico ${ }^{62}$. Esta situación llevó a que muchas familias de la aristocracia mallorquina pusieran sus ojos en universidades próximas geográficamente a la isla, como podían ser las de Barcelona, Orihuela, Tarragona, Gandía o Valencia ${ }^{63}$. Pero yendo todavía más lejos, también es cierto que durante el siglo XVI y parte del XVII, la nobleza de los territorios de la Corona de Aragón tuvo muy presente la Península Itálica para enviar

\footnotetext{
55. Montaner 1990, p. 76.

56. Vidal y de Barnola 1993, p. 49.

57. Montaner 1989, p. 10.

58. Montaner 1990, p. 83.

59. Ramis de Ayreflor i Sureda 1944-1946, p. 734

60. Barrio Gozalo 2002, p. 35.

61. Barrio Gozalo 2010b, p. 102.

62. García Pérez 2017c, p. 227.

63. Ramis Barceló 2015a, p. 477.
} 
allí a sus vástagos y que terminasen sus estudios universitarios ${ }^{64}$. Es por esto por lo que muchos aspirantes al Cabildo mallorquín se habían graduado en universidades de gran prestigio como la Universidad de Pisa o la Sapienza de Roma ${ }^{65}$. Sin embargo, durante la segunda mitad del siglo XVIII, la situación se había modificado sustancialmente.

Primeramente, hubo un crecimiento relativo, pero a la vez significativo, del número de doctores. Algunos canónigos lo eran ya cuando accedieron a la canonjía, concretamente veintiún miembros, una cifra superior a la primera mitad de la centuria. El peso que la Universidad Luliana y Literaria estaba asumiendo en la vida académica mallorquina, las reformas ilustradas que posibilitaron los obispos en el Seminario de San Pedro y el retorno de un espíritu tridentino casi perdido incentivaron este aumento de canónigos mejor preparados. Además, la dotación al Cabildo de las dos canonjías de oficio que todavía le faltaban en 1770 -concretamente la magistral y la doctoral-sirvió también para elevar el nivel de instrucción de sus miembros ${ }^{66}$. A fin de cuentas, los poseedores de dichas canonjías lo eran siempre por oposición y debían contar con un doctorado en la especialidad que se requiriese. Por eso, el primer canónigo doctoral de la Catedral de Mallorca, Antoni Bisquerra, era ya catedrático de Instituta en la Universidad ${ }^{67}$, y el primer magistral, Antoni Nicolau Lobo, se doctoró en Teología Luliana en 1745 y fue posteriormente Catedrático de Vísperas ${ }^{68}$. Además, hubo canónigos que consiguieron la borla de doctor una vez eran miembros del cuerpo capitular, como es el caso de Joan Dameto i Despuig, canónigo desde 1777, que se doctoró en Artes y Filosofía tres años después ${ }^{69}$.

Como en épocas pasadas, si la familia y el prestigio social no eran suficientes para conseguir adentrarse en el Cabildo de Mallorca, una esmerada formación universitaria podía hacer el resto. Por un lado, algunos colegiales de Nuestra Señora de la Sapiencia, un centro que dotaba la formación universitaria de jóvenes sin recursos económicos aspirantes al sacerdocio, consiguieron infiltrarse en el Cabildo tras acumular un brillante currículum. Es el caso de Josep Frau, que se convirtió en canónigo en 1743, o quizás el ejemplo más famoso del siglo XVIII, el Dr. Bernat Nadal, futuro obispo de Mallorca. Nacido en el seno de una familia humilde, Nadal recibió una beca en el colegio de la Sapiencia, se doctoró en Artes y Filosofía en 1764 y fue catedrático de Filosofía Luliana en la Universidad ${ }^{70}$. Tras distintos cargos eclesiásticos que engrandecieron su currículum y le convirtieron en un personaje de gran peso social, se convirtió en canónigo de Mallorca en 178771. Por otro lado, las relaciones de interdependencia universitaria se entretejían también

64. Ramis Barceló 2015b, p. 666.

65. Véase Ramis Barceló, 2017.

66. Barrio Gozalo, 2010b, p. 52.

67. Planas Rosselló y Ramis Barceló 2011, p. 83.

68. Cassanyes Roig y Ramis Barceló 2015, p. 101.

69. Cassanyes Roig y Ramis Barceló 2014. [Edición electrónica].

70. Ramis Barceló 2014, p. 205.

71. ACM, Libro de posesorios de las dignidades canónicas, sucentoría y pavordías de esta Santa Iglesia, núm. 15.576, f. 49r. 
con las redes clientelares tan propias de la Edad Moderna. Por ejemplo, el Dr. Antonio Seguí, doctorado en Roma en 1723, que consiguió infiltrarse en el Cabildo ese mismo año ${ }^{72}$. Una vez se hizo mayor, nombró coadjutor a su sobrino, el Dr. Miquel Seguí, que se sucedió en la canonjía en $1751^{73}$.

\section{LAS REFORMAS ILUSTRADAS Y LA AUTORIDAD RESTAURADA DE LOS OBISPOS DE MALLORCA}

La ascendencia social y religiosa que había asumido el Cabildo de Mallorca sobre los obispos era, a inicios del siglo XVIII, un hecho más que notable. Todos los intentos del episcopado por someter a unos canónigos plenamente conscientes de sus prerrogativas, así como del lugar privilegiado que ocupaban en la cúspide, terminaron en fracaso. A fin de cuentas, como recordaba el Cabildo a un obispo del siglo XVIII, por concordia antiquísima celebrada con prelados, se halla [el Cabildo] en posesión inmemorial de conocer, privar y multar a sus capitulares y a otro cualquier eclesiástico ${ }^{74}$. De modo que los canónigos se consideraban en muchos sentidos libres de la férrea mano diocesana.

Por supuesto, hubo intentos de paliar esta situación. Obispos como Pedro de Alagón (1684-1701) y Juan Fernández Zapata (1722-1729) sirvieron de ejemplo inspirador para sus sucesores. Alagón había intentado supervisar y oficiar personalmente las ceremonias religiosas que se celebraban en la Seo, lo cual provocó un enorme escándalo entre unos canónigos que no soportaban intromisión alguna y obligó al rey a intervenir y dictaminar algunas providencias en favor del prelado, como que los Prebendados no entren en el hueco de su silla hasta haber tomado el Obispo la suya ${ }^{75}$. En cuanto a Zapata, llegado a Mallorca en 1722, se valió de sus poderes para reprimir y castigar los enquistados desmanes y excesos que se vivían dentro de la Catedral $^{76}$. De tal modo que censuró sin titubear a varios canónigos por su asistencia a las comedias ${ }^{77}$, amonestó a otros por ausentarse de ciertos servicios religiosos en la Seo -como la ceremonia del vestir y desvestir del obispo-, e intervino en la administración del ceremonial catedralicio en el espacio del coro ${ }^{78}$.

Una de las tradicionales armas del Cabildo era el envío de representantes directamente a la Corte para denunciar, como ocurría en estos dos casos, unas medidas que consideraba excesivas a la vez que injustas. Y por lo general solía terminar saliendo victorioso. En el primer caso, Carlos II había dictaminado en un principio favorablemente para el obispo Alagón, pero las desmesuradas presiones del

72. Ramis Barceló, 2017, p. 221.

73. ACM, Libro de posesorios de las dignidades canónicas, sucentoría y pavordías de esta Santa Iglesia, núm. 15.576, f. 70r.

74. BBM, Fondo del Convento de San Francisco, leg. 3, s/f.

75. AHN, Clero, Sec. Reg. Leg. 925, s/f.

76. García Pérez, 2017a, p. 506.

77. Mateu Mairata 1985, p. 395.

78. ACM, Actas Capitulares, ACA, 1646, f. 359v. 
Cabildo terminaron con una solución que en apariencia iba a contentar a ambas partes $^{79}$. En cuanto a Zapata, fue trasladado a la diócesis de León en 1729. A partir de entonces, los siguientes obispos que ocuparon la mitra se contentaron con jugar a políticas pactistas, viendo mermadas sus atribuciones episcopales y quedando su poder de actuación muy limitado. Para cuando Carlos III subió al trono en 1759, los canónigos de la Catedral de Mallorca continuaban disfrutando de una situación totalmente envidiable, y todos los miembros del estamento eclesiástico temían la ira de un Cabildo que ya no respondía ante nadie. Sin embargo, el nuevo monarca preparó una batería de reformas en distintos ámbitos de la Iglesia española que también afectaron al clero capitular ${ }^{80}$.

Centrado en insuflar su autoridad absolutista en todos los sectores políticos, sociales y religiosos bajo sus dominios, Carlos III autorizó y secundó intervenciones estatales en asuntos espirituales [...]. [Un] auténtico abuso de poder con el deseo de conseguir una sujeción lo más completa posible de la Iglesia al Estado ${ }^{81}$. Para tal fin, se valió de una nueva generación de obispos españoles entregados activamente en su misión de limpiar sus respectivas diócesis de vicios y excesos heredados de épocas pasadas ${ }^{82}$. La misma expulsión de los jesuitas en 1767 constató los límites a los que estaba dispuesta a llegar la Corona con tal de reafirmar su poder. Por toda España, se renovó el espíritu de Trento, se prepararon ambiciosos planes en las respectivas diócesis destinados a mejorar la enseñanza del clero e incentivar el celo católico y se reforzó la autoridad de los obispos como reflejo del incuestionado poder que estaba acumulando la Corona de Carlos III.

El Concordato de 1753 había limitado ya el uso abusivo de la coadjutoría y la resigna por parte de los hijos de la nobleza, y estas nuevas reformas pretendían contribuir a mermar el excesivo autoritarismo del que se valía el Cabildo. En 1763, Carlos III nombraba obispo de Mallorca a Francisco Garrido de la Vega (1763$1772)^{83}$. De temple tranquilo y una actitud camaleónica, el nuevo prelado no abanderó ninguna campaña para restituir la autoridad episcopal al lugar que supuestamente le correspondía, pero sí que introdujo los primeros cambios. Sus casi diez años en la mitra se caracterizaron por un período de transición de un episcopado débil y obligado a pactar sus políticas con el Cabildo, a una nueva casta de obispos muy seguros del poder que emanaba de la silla diocesana. De hecho, fue precisamente con su sucesor, el obispo jerezano Juan Díaz de la Guerra (1772-1777), con quien el Cabildo vivió sus días más difíciles, llegando a verse privado de la imagen que proyectaba desde hacía siglos. En efecto, las políticas implantadas por Díaz de la Guerra encarnan a partes iguales el despliegue reformista puesto en marcha por la Corona y un renovado espíritu postridentino que parecía ya olvidado ${ }^{84}$. Valién-

79. ACM, Papeles Sueltos, 15677. Desavenencias entre el obispo Alagón y los canónigos, s/f.

80. Véase Martí Gelabert 2004.

81. Cortés Peña 1989, p. 27.

82. Martín Hernández 1984, p. 557.

83. Xamena y Riera 1986, p. 171.

84. Para un estudio más profundo de las políticas implantadas por el obispo Díaz de la Guerra en Mallorca, véase García Pérez 2017d. 
dose de un exagerado autoritarismo, el prelado implantó reformas impopulares, pero que en la práctica pretendían construir una nueva Iglesia mallorquina totalmente acorde al modelo oficial que Madrid propugnaba. Y el primer lugar en el que intervino el prelado fue, precisamente, el espacio de la Catedral ${ }^{85}$.

Nada más llegar a Mallorca, Díaz de la Guerra vivió sus primeros enfrentamientos con el Cabildo. Tras comprobar los canónigos que el obispo no iba a elegir a uno entre los suyos para el cargo de vicario general, así como la excesiva independencia con la que pretendía gobernar la diócesis, pusieron un sinnúmero de objeciones para la fundación de un nuevo hospicio, la dotación de becas para el decadente Seminario e incluso el reparto de prerrogativas para el oficio conjunto de las ceremonias catedralicias ${ }^{86}$. Las tensiones que se respiraban llegaron a su clímax el 30 de junio de 1773, día de San Pedro. En mitad de un sermón, el canónigo magistral de la Catedral dirigió sus ojos al prelado y le recordó que las redes que echó Pedro al mar, le mandó Cristo que no fue solo, sino es con todos sus compañeros, en que reprendía [el magistral] al $R$. Obispo porque no se valía de los canónigos para dar sus providencias ${ }^{87}$. A partir de ese momento, Díaz de la Guerra no solo no pactó sus políticas con el Cabildo, sino que hizo lo inimaginable años atrás para consolidar su autoridad y, en muchos sentidos, restaurar los poderes episcopales de los que, en la práctica, parecía haber sido privado.

A similitud del obispo Zapata, Díaz de la Guerra también intentó erradicar actitudes impropias de un canónigo. Un año después de aquel sermón, mientras los canónigos le vestían para el oficio de una misa, el prelado notó que don Francisco Ferrer de Sant Jordi, antiguo rector de la Universidad de Mallorca, estaba ebrio. Pocas semanas después, llegó a sus oídos que, en mitad de la boda de su sobrina, el canónigo bebió tanto que, para evitar el escándalo de los criados, fue preciso bajarlo por fuera a un cuarto entresuelo y excitarle a vómito ${ }^{88}$. El prelado ordenó sin más dilación el encierro de Ferrer de Sant Jordi en la Casa de la Misión. Cuando este respondió que no podía ir, porque tenía que reclamar, por ser canónigo, tener varias Comisiones y no poder corregirle el Rdo. Obispo ${ }^{89}$, Díaz de la Guerra no se amilanó. Utilizando su influencia en la Real Audiencia, consiguió que un número reducido de alguaciles se presentase en la casa del canónigo para prenderlo. Aunque Ferrer de Sant Jordi pudo librarse finalmente del castigo, tuvo que trasladarse a Madrid como representante del Cabildo de Mallorca en la Corte.

A continuación, hubo otro asunto que enturbió las ya insalvables relaciones entre el obispo y el Cabildo. En Mallorca se tributaba culto desde tiempos inmemoriales al beato mallorquín Ramón Llull ${ }^{90}$. Desde hacía siglos, sus restos eran

85. García Pérez 2017b, p. 404.

86. García Pérez 2017c, p. 234.

87. AHN, Consejos, L. 1948, f. 226r.

88. AHN, Consejos, L. 1944, f. 618v.

89. AHN, Consejos, L. 1944, f. $618 \mathrm{v}$.

90. Desde que el erudito, filósofo y teólogo medieval Ramón Llull (1232-1315/16) murió, se desarrolló un potente culto religioso dedicado a su persona propio de la isla de Mallorca. Con sus restos mortales descansando en la iglesia de San Francisco, se le dedicaban dos fiestas anuales que conmemoraban su conversión religiosa y su martirio. La mayoría de iglesias de la isla incluían en su 
continuamente venerados, sus imágenes poblaban la mayoría de las iglesias y conventos de Mallorca, y las fiestas que se le dedicaban eran una fecha obligada en los calendarios litúrgicos ${ }^{91}$. Sin embargo, se trataba también de un culto plagado de enormes discordias. La figura controvertida del que llamaban el Doctor Iluminado tenía dividida a la población mallorquina desde hacía muchos años, lo que había desencadenado auténticos disturbios populares relacionados con la devoción. Si tenemos presente que por toda la península se estaban extirpando devociones populares y locales mal vistas o que no terminaban de casar con la línea trazada por la Corona, podrá entenderse por qué Díaz de la Guerra nunca vio con buenos ojos el lulismo ${ }^{92}$. De hecho, el obispo consideró que aquella devoción era ilegítima y debía ser erradicada. Y para tal fin, desplegó una batería de edictos que censuraban todos los ámbitos del que era llamado el Culto Público. Por su parte, los canónigos de la Catedral, que eran sus abyectos defensores junto con el Ayuntamiento de Palma, el profesorado universitario y las principales órdenes religiosas, intentaron frenar aquella represión devocional. Pero el prelado se valió, una vez más, de aquel asunto para someter al Cabildo al completo y devolverlo a su redil.

Introduciendo su sombra en el espacio de la Seo, Díaz de la Guerra ordenó bajo pena de 50 libras [que se] quitase una Estampa del Beato Raymundo Lulio con título y dictados de Santo que había en dicha Sacristía por estar estas prohibidas con Decreto $^{93}$. Tras constatar que los canónigos se negaban en redondo a obedecer, el prelado extorsionó a los beneficiados y al servicio doméstico de la Catedral, consiguiendo finalmente que el custodio entregase sus llaves de la sacristía al deán, con dimisión del empleo, y a mi Provisor [de la curia episcopal] una de las dos estampas que únicamente tenía ${ }^{94}$. Poco tiempo después, en paralelo a la persecución antiluliana que desplegó por toda la isla, Díaz de la Guerra decretó el que sin duda fue uno de sus más impopulares edictos, prohibiendo que, en lo futuro, en ningún caso y por ninguna causa o importunidad, los párrocos ni vicarios pongan [a] los bautizandos el nombre de Raymundo Lulio ${ }^{95}$. En lo que a la Catedral se refiere, aquello privaba a los canónigos de su tradicional independencia a la hora de actuar dentro de la Seo, por lo que un reducido grupo de canónigos decidió finalmente rebelarse y organizó un fastuoso bautizo en la Catedral $^{96}$.

Ocupándose de que la noticia llegase al Palacio Episcopal, los canónigos Antoni Nicolau Lobo, Nicolau Villalonga y Antoni Moragues bautizaron a un niño, y

\footnotetext{
programa iconográfico estatuas, tallas y cuadros de Llull, generaciones de padres bautizaban a sus hijos incluyendo su nombre y existía la creencia generalizada de que el Beato intercedía ante el Altísimo para traer las lluvias a Mallorca, una idea que casaba perfectamente con el culto que se prodigaba a santos y beatos en la Europa Moderna. Desde muy pronto, las élites mallorquinas conocieron los beneficios positivos del que era llamado el Culto Público, especialmente de cara a prevenir posibles disturbios y amotinamientos populares motivados por carestías y redirigiendo el malestar popular hacia aquellas ceremonias. Véase García Pérez 2017d.

91. Ferrer Flórez 2001, p. 65.

92. García Pérez, 2014a, p. 408.

93. ACM, Actas Capitulares, ACA 1660, f. 284r.

94. ACM, CPS 18466, Caja 314, núm. 44, s/f.

95. AMP, Actas Municipales, AH, 2101/1, f. 248r.

96. García Pérez, 2017d, p. 283.
} 
entre otros nombres que se le impuso al bautizado fue uno de ellos el de Raymundo Lulio, lo que directamente se opone a lo mandado por su Señoría Ilustrísima ${ }^{97}$. A continuación, Díaz de la Guerra procedió con excesivo rigor y trazó su pequeña venganza con el canónigo magistral, Antoni Nicolau Lobo, privándole desde ese momento de predicar y confesar ${ }^{98}$. Finalmente, la respuesta popular para salvar aquella devoción de su extinción fue tan desaforada, que Carlos III se vio obligado a intervenir y ordenó la marcha inmediata del obispo Díaz de la Guerra a la Corte para responder por sus políticas. Aquello fue interpretado por el Cabildo como una nueva victoria, a imagen de lo que había ocurrido cincuenta años atrás con Fernández Zapata. Pero pronto salieron de su engaño, pues el Consejo de Castilla terminó de dinamitar su tradicional y exagerada autoridad.

Aprovechando la partida de Díaz de la Guerra a Madrid, el Cabildo había utilizado el período de sede vacante para restaurar la devoción luliana en los altares, ordenando que repongan los cuadros de Raymundo Lulio, que han faltado de sus iglesias, en el tiempo que estaban a su cuidado, al lugar y sitio en que estaban colocados $^{99}$. Pero no contentos con aquello, los canónigos llegaron todavía más lejos para recuperar su antiguo poder. De tal modo que confeccionaron una extensa lista que incluía a todos los curas párrocos, vicarios, sacristanes y miembros de órdenes religiosas que habían colaborado con el anterior prelado en la persecución de aquella devoción ${ }^{100}$. Desde ese momento, todos ellos quedaban privados de confesar y predicar hasta nueva orden. Algunos de los castigados denunciaron inútilmente ante la Real Audiencia que nadie puede ser despojado de su posesión sin ser primero citado, oído y vencido en juicio, y que el que de otro modo es arrojado de ella con autoridad privada, o con la del juez, debe ser antes de todo restituido ${ }^{101}$. Por supuesto, aquella situación pronto llegó a oídos de Madrid y, a finales de aquel año de 1777, el abogado y representante del Cabildo ante el Consejo de Castilla oyó decir que el Cabildo [de Mallorca] estaba lleno de discordias [...] y consistían en que un partido quería que se hiciese la oposición rigurosa ${ }^{102}$.

Cuando Carlos III presentó la candidatura de un nuevo obispo para la mitra mallorquina, se aseguró de que jamás volviese a repetirse una situación igual y revistió al prelado electo con el apoyo total de la Corona. De modo que cuando Pedro Rubio-Benedicto y Herrero llegó a Mallorca en 1778, el Cabildo catedralicio fue especialmente informado por el presidente del Consejo de Castilla del sumo desagrado que han causado a S.M. y al Consejo las muchas expresiones injuriosas y notorias calumnias que han vertido en todas sus representaciones contra el citado Rdo. Obispo ${ }^{103}$. A continuación, y por deseo expreso del rey, se informó también a los canónigos de que en caso de contravención se procederá contra el

97. BBM, Fondo del Convento de San Francisco, leg. 2, f. 1r.

98. ACM, Actas Capitulares, ACA 1661, f. 289v.

99. ARM, Audiencia, AA, 757/4, s/f.

100. García Pérez 2017a, p. 520.

101. ARM, Audiencia, AA, 762/1, s/f.

102. BBM, Epistolario de Miguel Cayetano Soler con el canónigo Raimundo Togores, carta 16.

103. ACM, Actas Capitulares ACA, 1662, f. 137v. 
que sea inobediente por los términos más conducentes a proteger a los Prelados eccos. para que sean obedecidos y respetados por sus súbditos ${ }^{104}$. Además, el rey recordó a su capitán general en Mallorca que debe la Real Audiencia impartirle el auxilio para un cumplimiento por ser pura cuestión de hecho ${ }^{105}$.

Por su propia personalidad, el obispo Rubio-Benedicto se caracterizó siempre por ser un hombre de temple tranquilo, totalmente desprovisto de ansias autoritarias y dispuesto siempre al diálogo, pero, aunque no hubiese sido así, el episcopado contaba ahora con el apoyo total que le brindaba la Corona, preservándole de volver a vivir situaciones como las que habían experimentado algunos de sus antecesores. Bajo su pontificado, la autoridad episcopal había sido finalmente restaurada y el Cabildo catedralicio se había visto obligado a jugar según nuevas reglas.

\section{CONCLUSIONES}

La segunda mitad del siglo XVIII testimonió importantes cambios dentro del Cabildo de Mallorca que rompieron con siglos de tradición. De hecho, muchos de los engranajes que se habían perfeccionado a lo largo del Seiscientos y habían consolidado no solo el poder y ascendiente social que ejercían los canónigos, sino también su completo control sobre la provisión de las prebendas, pasaron al olvido. En primer lugar, la firma del Concordato entre la Santa Sede y Fernando VI en 1753 conllevó el final de siglos de indiscriminada patrimonialización de las prebendas capitulares mediante el uso de la coadjutoría y la resigna. La primera, de hecho, fue una de las estrategias favoritas del Cabildo mallorquín, dándose un crecimiento constante de su uso durante el siglo XVII y llegando a su clímax en los primeros cincuenta años del siglo XVIII. Sin embargo, tras el Concordato, la coadjutoría desaparece en el primer lustro después de su firma.

Obviamente, esta circunstancia puede hacer creer fácilmente que habían terminado siglos de políticas clientelares y patrimonialistas dentro del Cabildo, pero la realidad no siempre fue así. Porque, aunque es cierto que la presentación de miembros recaía principalmente en la Corona, las grandes familias mallorquinas consiguieron valerse de otros mecanismos menos directos para seguir infiltrando a sus vástagos en la Catedral. Lo que realmente se observa a partir de entonces es un proceso de adaptación por parte de aquellas estirpes a las cambiantes circunstancias que se abrían paso, buscando nuevas formas indirectas de patrimonialización, pero que continuasen asegurando su predominio en el intrincado universo de las prebendas capitulares. Por eso mismo, a partir de 1753, con la coadjutoría y la resigna pasando paulatinamente al olvido, los grandes apellidos mallorquines supieron hallar otros mecanismos para perpetuarse en las prebendas y continuar infiltrando en la Catedral a sus respectivos familiares y clientes. El ejemplo para-

104. AHN, Consejos, L. 1948, f. 228r.

105. AHN, Consejos, L. 1948, f. 218 r.

HID 45 (2018) 61-87

ISSN: 0210-7716 ISSN-e 2253-8291

http://dx.doi.org/10.12795/hid.2018.i45.03 
digmático nos lo ofrece la familia Despuig, que consiguió mantenerse en la dignidad de chantre, sin usar ya la coadjutoría o la resigna para ello.

Otra de las consecuencias directas del Concordato fue una intromisión más firme dentro de la Seo por parte de obispos. Y esta se dio a través distintas vías. Primeramente, aumentó levemente el número de promociones de integrantes por prelados, si bien ya se habían dado algunos casos a inicios de siglo. La colocación en el Cabildo de potenciales colaboradores era una estrategia con la que el episcopado pretendía reforzar su poder de actuación en la cúspide, especialmente teniendo presentes las serias limitaciones que había experimentado la autoridad diocesana durante el siglo XVII. Pero si estas políticas no daban resultado, había mecanismos más firmes e impopulares para someter a los canónigos. Tras la subida al trono de Carlos III, se animó a los obispos para que incrementasen sus fuerzas a fin de asumir cotas de poder capaces de implantar las reformas que se estaban planificando. La reimposición de un espíritu postridentino prácticamente olvidado y la decidida intención de la Corona de extirpar desmanes y excesos muy enquistados entre el clero católico bajo sus dominios motivaron este aumento del autoritarismo episcopal.

En lo que a la Catedral mallorquina se refiere, los obispos de la segunda mitad del siglo XVIII intentaron paliar las tradicionales políticas pactistas que venían repitiéndose con los canónigos. Y por encima de todos ellos destaca el obispo jerezano Juan Díaz de la Guerra. Durante sus cinco años en la mitra mallorquina, el prelado intentó de muy diversos modos someter al Cabildo y consolidar sus poderes episcopales. Por ello, el furibundo sermón que predicó el canónigo magistral contra su persona, la reiterada presencia en la Catedral de un canónigo con problemas de alcoholismo, la asistencia de estos a las comedias y el patronazgo de un culto religioso local que no contaba con el beneplácito papal, fueron motivos más que suficientes para erradicar aquella situación. De modo que privó de predicar y confesar a algunos canónigos, menoscabó la jurisdicción del Cabildo sobre los santos sacramentos dentro de la Seo y se adjudicó todo lo relacionado con el Seminario de San Pedro. El Cabildo, como muchas otras veces antes, se valió del recurso de dirigirse a la Corona y denunciar los procederes del prelado, pero esta vez, el actual obispo, como sus homólogos peninsulares, contaba ya con la total connivencia de Carlos III.

A partir de1778, y a raíz de los disturbios que se vivieron en la diócesis mallorquina por las políticas antilulistas del prelado, el Consejo de Castilla incidió en la necesidad de reforzar los poderes episcopales y aprovechó el nombramiento de un nuevo prelado, Pedro Rubio-Benedicto y Herrero, para revestirlo con una autoridad ya incuestionada y que contaba con la protección del capitán general de Mallorca y su Real Audiencia. Además, el mismo monarca advirtió a los canónigos que no iba a tolerar ningún tipo de desafección o resistencia a cumplir los procederes del nuevo prelado. Esto significaba, por otro lado, que el envío tradicional a la Corte de representantes del Cabildo para denunciar distintas situaciones, como podía ser el supuesto abuso de poder por parte de un prelado, se había terminado. 
Pasando a otro ámbito, el Cabildo de la segunda mitad del siglo XVIII continuó manteniendo un exagerado predominio de las familias nobles de Mallorca. Como en momentos anteriores, los apellidos de las principales estirpes, incluyendo, claro está, a las conocidas como las antiguas Nou Cases, siguen repitiéndose. Sin embargo, también es cierto que continuaron accediendo algunas de las familias más poderosas económicamente de la isla, consiguiendo infiltrarse también en instituciones civiles de prestigio como los ayuntamientos. Durante la segunda mitad del Setecientos, el uso del prenotado Don, que durante tantos años había caracterizado primeramente al estamento más elevado del brazo noble, se generalizó hasta cotas altísimas. De tal modo que el 99\% de los canónigos pasaron a usarlo, desapareciendo el uso del tradicional Magnific para el estamento de cavallers que se veía en los siglos XVI y XVII. Además, la dotación a la isla de Mallorca de una infraestructura universitaria propia permitió que ya no fuera necesario viajar a otras universidades para conseguir la borla de Doctor, por ejemplo. La presencia de aspirantes al Cabildo que contaban ya con un doctorado aumentó en aquellos años, y otros que no lo tenían pudieron conseguirlo fácilmente, sin necesidad, por ejemplo, de aprovechar sus estancias en Roma para ello.

Anexo. Los Canónigos de la CATEdRal de MallorCa (1750-1800)

\begin{tabular}{|c|c|c|}
\hline NOMBRE & $\begin{array}{l}\text { PERÍODO EN } \\
\text { EL CARGO }\end{array}$ & OBSERVACIONES \\
\hline \multicolumn{3}{|c|}{ Deán } \\
\hline Sr. Don Joan Despuig i Fortuny & $1751-1780$ & $\begin{array}{l}\text { Promovido por el Obispo Llorenç } \\
\text { Despuig i Cotoner, su primo, que le } \\
\text { nombró también vicario general. }\end{array}$ \\
\hline Sr. Don Martí Pou & $1780-1787$ & \\
\hline Sr. Dr. Don Josep Montes & $1787-1824$ & \\
\hline \multicolumn{3}{|c|}{ Sacristán } \\
\hline Sr. Don Joan de Togores i Salas & $1745-1792$ & $\begin{array}{l}\text { Sucedió en la canonjía a su tío, Don } \\
\text { Ramon de Togores, pero no se valió } \\
\text { de la coadjutoría o resigna. }\end{array}$ \\
\hline Sr. Don Joan Dameto i Despuig & $\begin{array}{c}1792-(\text { no } \\
\text { consta) }\end{array}$ & \\
\hline \multicolumn{3}{|c|}{ Arcediano } \\
\hline Sr. Don Jaume Terrassa & $1751-1808$ & $\begin{array}{l}\text { Coadjutor de su tío, Don Miquel Te- } \\
\text { rrassa. }\end{array}$ \\
\hline \multicolumn{3}{|c|}{ Chantre } \\
\hline $\begin{array}{l}\text { Sr. Don Ramon Despuig i For- } \\
\text { tuny }\end{array}$ & $1750-1758$ & \\
\hline
\end{tabular}




\begin{tabular}{|c|c|c|}
\hline NOMBRE & $\begin{array}{l}\text { PERÍODO EN } \\
\text { EL CARGO }\end{array}$ & OBSERVACIONES \\
\hline Sr. Don Joan Despuig i Despuig & $1758-1761$ & $\begin{array}{l}\text { Accede por resigna de Don Ramon } \\
\text { Despuig i Fortuny. }\end{array}$ \\
\hline $\begin{array}{l}\text { Sr. Don Llorenç Despuig i Des- } \\
\text { puig }\end{array}$ & $1761-1786$ & $\begin{array}{l}\text { Accede por resigna de Don Joan } \\
\text { Despuig i Despuig. }\end{array}$ \\
\hline $\begin{array}{l}\text { Sr. Don Antoni Despuig i Da- } \\
\text { meto }\end{array}$ & $1786-1791$ & $\begin{array}{l}\text { Archivero del Cabildo. } \\
\text { Nombrado cardenal por Pío VII. } \\
\text { Obispo de Orihuela (1791-1795) } \\
\text { Arzobispo de Sevilla (1795-1799) }\end{array}$ \\
\hline $\begin{array}{l}\text { Sr. Don Joan Despuig i Za- } \\
\text { forteza }\end{array}$ & $1791-1810$ & \\
\hline \multicolumn{3}{|c|}{ Tesorero } \\
\hline Sr. Don Antoni Dameto i Pueyo & $1755-1790$ & $\begin{array}{l}\text { Abandona el Cabildo tras contraer } \\
\text { matrimonio. }\end{array}$ \\
\hline Sr. Don Gabriel Olivar & $1790-1792$ & \\
\hline Sr. Don Cristòfol Cladera & $1792-1817$ & \\
\hline \multicolumn{3}{|c|}{ Canonjía presbiteral I } \\
\hline Sr. Don Joan Despuig i Fortuny & $1733-1780$ & Posteriormente dignidad de deán. \\
\hline Sr. Don Martí Torrens & $1780-1800$ & \\
\hline \multicolumn{3}{|c|}{ Canonjía presbiteral II } \\
\hline Sr. Miquel Barceló & $1743-1777$ & $\begin{array}{l}\text { Accede tras la muerte de su tío, Don } \\
\text { Miquel Valls. }\end{array}$ \\
\hline Sr. Don Joan Dameto i Despuig & $1777-1792$ & Posteriormente dignidad de sacristán. \\
\hline Sr. Don Antoni Vila i Camps & $1792-1798$ & Obispo de Menorca (1798-1802). \\
\hline Sr. Don Pere Josep Molinas & $1798-1830$ & \\
\hline \multicolumn{3}{|c|}{ Canonjía presbiteral III } \\
\hline Sr. Don Pasqual Dezcallar & $1751-1792$ & \\
\hline Sr. Don Jordi Puigdorfila & $1792-1828$ & \\
\hline \multicolumn{3}{|c|}{ Canonjía presbiteral IV } \\
\hline $\begin{array}{l}\text { Sr. Don Joaquim Dameto i } \\
\text { Pueyo }\end{array}$ & $1755-1755$ & \\
\hline Sr. Don Jaume Sureda & $1755-1798$ & $\begin{array}{l}\text { Coadjutor de Don Joaquim Dameto } \\
\text { i Pueyo. }\end{array}$ \\
\hline Sr. Don Joan Morell & $1798-1806$ & \\
\hline \multicolumn{3}{|c|}{ Canonjía presbiteral V } \\
\hline Sr. Don Josep Frau & $1743-1762$ & $\begin{array}{l}\text { Se doctoró en Roma en } 1746^{*} . \\
\text { Colegial de la Sapiencia**. }\end{array}$ \\
\hline Sr. Dr. Don Pere Orlandis & $1762-1803$ & \\
\hline
\end{tabular}




\begin{tabular}{|c|c|c|}
\hline NOMBRE & $\begin{array}{l}\text { PERÍODO EN } \\
\text { EL CARGO }\end{array}$ & OBSERVACIONES \\
\hline \multicolumn{3}{|c|}{ Canonjía presbiteral VI } \\
\hline Sr. Dr. Don Jaume Oliver & $1764-1795$ & \\
\hline Sr. Don Joan Muntaner i García & $1795-1847$ & $\begin{array}{l}\text { Vicario general gobernador entre } \\
1811 \text { y } 1813 \text {, durante la ausencia del } \\
\text { obispo Bernat Nadal. } \\
\text { Murió siendo Obispo electo de Ca- } \\
\text { racas. } \\
\text { Catedrático de Vísperas de Cáno- } \\
\text { nes***. }\end{array}$ \\
\hline \multicolumn{3}{|c|}{$\begin{array}{c}\text { Canonjía presbiteral VII } \\
\text { (Canonjía doctoral desde 1770) }\end{array}$} \\
\hline Sr. Don Gabriel Ballester & $1744-1758$ & $\begin{array}{l}\text { Coadjutor de Don Gabriel Ballester, } \\
\text { su tío. }\end{array}$ \\
\hline Sr. Dr. Don Joaquim de Pueyo & $1758-1771$ & \\
\hline Sr. Don Antoni Bisquerra & $1771-1796$ & $\begin{array}{l}\text { Primer canónigo doctoral. } \\
\text { Fue elegido para el obispado de Al- } \\
\text { barracín, pero lo rechazó. }\end{array}$ \\
\hline Sr. Don Pere Roig & $1796-1812$ & $\begin{array}{l}\text { Vicario general del obispo Bernat } \\
\text { Nadal. }\end{array}$ \\
\hline \multicolumn{3}{|c|}{$\begin{array}{c}\text { Canonjía presbiteral VIII } \\
\text { (Canonjía magistral desde 1770) }\end{array}$} \\
\hline $\begin{array}{l}\text { Sr. Don Nicolau Femenia i Llo- } \\
\text { rens }\end{array}$ & $1724-1773$ & Coadjutor de Don Jaume Llorens. \\
\hline Sr. Don Antoni Nicolau Lobo & $1773-1807$ & $\begin{array}{l}\text { Primer canónigo magistral. } \\
\text { Fue privado de predicar y confesar } \\
\text { por el obispo Juan Díaz de la Guerra } \\
\text { tras su resistencia a distintos edictos } \\
\text { episcopales. } \\
\text { Catedrático de Teología Luliana****. }\end{array}$ \\
\hline \multicolumn{3}{|c|}{ Canonjía presbiteral IX } \\
\hline $\begin{array}{l}\text { Sr. Dr. Don Joan Bautista Ferrer } \\
\text { de Sant Jordi }\end{array}$ & $1747-1774$ & \\
\hline $\begin{array}{l}\text { Sr. Don Antoni Despuig i Da- } \\
\text { meto }\end{array}$ & $1774-1792$ & $\begin{array}{l}\text { Auditor de la Rota Romana } \\
\text { Nombrado cardenal por Pío VII } \\
\text { Chantre de la Catedral en } 1786 \\
\text { Obispo de Orihuela (1791-1795) } \\
\text { Arzobispo de Sevilla (1795-1799) }\end{array}$ \\
\hline Sr. Don March Carreras & $1792-1802$ & \\
\hline
\end{tabular}




\begin{tabular}{|c|c|c|}
\hline NOMBRE & $\begin{array}{l}\text { PERÍODO EN } \\
\text { EL CARGO }\end{array}$ & OBSERVACIONES \\
\hline \multicolumn{3}{|c|}{ Canonjía penintenciaria } \\
\hline Sr. Don Bartomeu Nebot & $1752-1765$ & \\
\hline Sr. Don Nicolau Obrador & $1765-1778$ & \\
\hline Sr. Don Pere Sard & $1778-1795$ & \\
\hline Sr. Don Pere Torrandell & $1795-1803$ & Rector de Llucmajor. \\
\hline \multicolumn{3}{|c|}{ Canonjía diaconil I } \\
\hline Sr. Dr. Don Cristòfol Martorell & $1741-1782$ & $\begin{array}{l}\text { Coadjutor de Don Joan Baptista } \\
\text { Palou. }\end{array}$ \\
\hline Sr. Don Llorenç Serra i Rotger & $1782-1808$ & \\
\hline \multicolumn{3}{|c|}{ Canonjía diaconil II } \\
\hline $\begin{array}{l}\text { Sr. Dr. Don Pere Joan de Puig- } \\
\text { dorfila }\end{array}$ & $1742-1787$ & \\
\hline Sr. Dr. Don Bernat Nadal & $1787-1794$ & Obispo de Mallorca (1794-1818). \\
\hline Sr. Don Joaquim Cotoner & $1794-1836$ & \\
\hline \multicolumn{3}{|c|}{ Canonjía diaconil III } \\
\hline Sr. Don Joan Dezcallar & $1758-1787$ & \\
\hline Sr. Don Miquel Serra i Dameto & $1787-1830$ & \\
\hline \multicolumn{3}{|c|}{ Canonjía diaconil IV } \\
\hline Sr. Don Joan Riusech & $1754-1760$ & \\
\hline Sr. Don Ramon Togores & $1760-1788$ & \\
\hline Sr. Don March Antoni Truyols & $1788-1829$ & \\
\hline \multicolumn{3}{|c|}{$\begin{array}{c}\text { Canonjía diaconil V } \\
\text { (siempre mediante provisión real) }\end{array}$} \\
\hline $\begin{array}{l}\text { Sr. Dr. Don Francesc Ferrer de } \\
\text { Sant Jordi }\end{array}$ & $1760-1802$ & $\begin{array}{l}\text { Enviado a Madrid por el Cabildo } \\
\text { para no ser internado en la Casa de } \\
\text { la Misión por orden del obispo Díaz } \\
\text { de la Guerra. }\end{array}$ \\
\hline \multicolumn{3}{|c|}{ Canonjía diaconil VI } \\
\hline $\begin{array}{l}\text { Sr. Don Ramon Despuig i For- } \\
\text { tuny }\end{array}$ & $1752-1775$ & \\
\hline Sr. Don Francesc de Togores & $1775-1789$ & \\
\hline Sr. Don Joan Colom & $1789-1806$ & \\
\hline \multicolumn{3}{|c|}{ Canonjía subdiaconil I } \\
\hline Sr. Don Francesc Güells & $1733-1776$ & $\begin{array}{l}\text { Coadjutor de Don Francesc Mir, su } \\
\text { tío. }\end{array}$ \\
\hline Sr. Don Joan Barceló & $1776-1815$ & \\
\hline
\end{tabular}




\begin{tabular}{|c|c|c|}
\hline NOMBRE & $\begin{array}{l}\text { PERÍODO EN } \\
\text { EL CARGO }\end{array}$ & OBSERVACIONES \\
\hline \multicolumn{3}{|c|}{ Canonjía subdiaconil II } \\
\hline $\begin{array}{l}\text { Sr. Don Francesc Truyols i Ros- } \\
\text { sinyol }\end{array}$ & $1740-1786$ & \\
\hline Sr. Dr. Don Martí Tous & $1786-1815$ & Deán de la Catedral. \\
\hline \multicolumn{3}{|c|}{ Canonjía subdiaconil III } \\
\hline Sr. Dr. Miquel Seguí & $1751-1789$ & $\begin{array}{l}\text { Coadjutor del Dr. Don Antoni Seguí, } \\
\text { su tío. }\end{array}$ \\
\hline Sr. Dr. Don Josep Montes & $1789-1824$ & \\
\hline \multicolumn{3}{|c|}{$\begin{array}{c}\text { Canonjía lectoral } \\
\text { (desde 1714) }\end{array}$} \\
\hline $\begin{array}{l}\text { Dr. Don Nicolau Villalonga i } \\
\text { Truyols }\end{array}$ & $1754-1808$ & $\begin{array}{l}\text { Vicario general sede vacante entre } \\
1777 \text { y } 1778 .\end{array}$ \\
\hline \multicolumn{3}{|c|}{ Canonjía subdiaconil V } \\
\hline Sr. Don Antoni Moragues & $1756-1777$ & $\begin{array}{l}\text { Coadjutor de Don Jaume Moragues, } \\
\text { su tío. }\end{array}$ \\
\hline Sr. Don Ferran Truyols & $1777-1783$ & \\
\hline Sr. Dr. Don Josep Quadrado & $1783-1807$ & \\
\hline \multicolumn{3}{|c|}{ Canonjía subdiaconil VI } \\
\hline $\begin{array}{l}\text { Sr. Don Nicolau Truyols i For- } \\
\text { tuny }\end{array}$ & $1752-1763$ & \\
\hline Sr. Don Onofre Barceló & $1763-1824$ & \\
\hline \multicolumn{3}{|c|}{ Sochantre } \\
\hline Sr. Don Miquel Rossinyol & $1751-1770$ & $\begin{array}{l}\text { Abandona el Cabildo tras contraer } \\
\text { matrimonio. }\end{array}$ \\
\hline Sr. Don Bernardí Rosselló & $1770-1815$ & \\
\hline \multicolumn{3}{|c|}{ Pavordía del coro de la parte del obispo I } \\
\hline Sr. Dr. Don Josep Reus & $1743-1792$ & \\
\hline Sr. Dr. Don Joan Binimelis & $1792-1825$ & $\begin{array}{l}\text { Vicario General del Obispo Pedro } \\
\text { Rubio-Benedicto y Herrero. } \\
\text { Catedrático de Teología Luliana*****. } \\
\text { Presentado a pavorde de la Catedral } \\
\text { por el obispo. }\end{array}$ \\
\hline \multicolumn{3}{|c|}{ Pavordía del coro de la parte del obispo II } \\
\hline Sr. Don Antoni Nicolau Lobo & $1751-1773$ & $\begin{array}{l}\text { Primer canónigo magistral. } \\
\text { Catedrático de Teología Luliana. }\end{array}$ \\
\hline Sr. Juan Ballester & $1773-1787$ & \\
\hline Sr. Pere Julià & $1787-1827$ & \\
\hline
\end{tabular}




\begin{tabular}{|c|c|c|}
\hline NOMBRE & $\begin{array}{c}\text { PERÍODO EN } \\
\text { EL CARGO }\end{array}$ & OBSERVACIONES \\
\hline \multicolumn{3}{|c|}{ Pavordía del coro de la parte del arcediano I } \\
\hline Sr. Don Guillem Terrassa & $1701-1780$ & \\
\hline Sr. Don Rafel Llompard & $1780-1805$ & \\
\hline \multicolumn{3}{|c|}{ Pavordía del coro de la parte del arcediano II } \\
\hline $\begin{array}{l}\text { Sr. Don Nicolau Villalonga i } \\
\text { Truyols }\end{array}$ & $1749-1784$ & $\begin{array}{l}\text { Promovido por el obispo José de Ce- } \\
\text { peda. }\end{array}$ \\
\hline Sr. Don Jordi Puigdorfila & $1784-1795$ & $\begin{array}{l}\text { Promovido por el obispo Pedro Ru- } \\
\text { bio-Benedicto y Herrero. }\end{array}$ \\
\hline Sr. Don Francesc Vich & $1784-1801$ & \\
\hline
\end{tabular}

* Ramis Barceló 2017, p. 231.

** Ramis Barceló 2014, p. 18.

*** Planas Rosselló y Ramis Barceló 2011, p. 86.

**** Cassanyes Roig y Ramis Barceló 2014, p. 204.

***** Cassanyes Roig y Ramis Barceló 2014, p. 204.

\section{BiBLIOGRAFÍA CITADA}

Alcina, Llorenç (1985), "La formació teològica per al ministeri presbiterial en la història de l'Església de Mallorca”, Comunicació, 40-41, pp. 3-21.

Amengual i Batle, Josep (2001), Història de l'Església de Mallorca. Del Barroc a la Il-lustració (1563-1800), Palma.

Barceló Crespí, Maria y Ensenyat Pujol, Gabriel (2014), Clergues il·lustrats. Un cercle humanista a l'entorn de la Seu de Mallorca (1450-1550), Palma.

Barrio Gozalo, Maximiliano (2002), "Sociología del alto clero en la España del siglo ilustrado", Manuscrits, 20, pp. 29-59.

Barrio Gozalo, Maximiliano (2010a), El clero en la España Moderna, Córdoba.

Barrio Gozalo, Maximiliano (2010b), El sistema beneficial de la Iglesia española en el Antiguo Régimen (1475-1734), Alicante.

Beltrán Almozán, Cristóbal y Toledano Galera, Juan (1988), "El Cabildo de la Catedral de Jaén en el siglo XVI. Organización y funcionamiento", Boletín del Instituto de Estudios Giennenses, 134, pp. 31-58.

Burón Castro, Taurino (2006), "Dignidades y canónigos de la Catedral de León", Memoria Ecclesiae, 29, pp. 209-225.

Cassanyes Roig, Albert y Ramis Barceló, Rafael (2014), “Los graduados en Artes y Filosofía en la Universidad Luliana y Literaria de Mallorca II (1750-1831)", Tiempos Modernos, 29 [Edición electrónica].

Cassanyes Roig, Albert y Ramis Barceló, Rafael (2015), "Los grados en Teología luliana en la Universidad de Mallorca (1692-1824)", Bolleti de la Societat Arqueològica Lul-liana, 71, pp. 93-127.

Cortés Peña, Antonio Luis (1989), La política religiosa de Carlos III, Granada. 
Díaz Rodríguez, Antonio J. (2009), "El precio del nepotismo. Coadjutoría y resigna en las catedrales andaluzas (ss. XVI-XVIII)", Chronica Nova, 35, pp. 287-309.

Díaz Rodríguez, Antonio J. (2012), El clero catedralicio en la España Moderna: los miembros del Cabildo de la Catedral de Córdoba (1475-1808), Murcia.

Díaz Rodríguez, Antonio J. y López-Salazar Codes, Ana Isabel (2014), "El Cabildo catedralicio de Évora en la Edad Moderna (1547-1801)", Historia y Genealogía, 4, pp. 31-58.

Escámez Mañas, Francisco José (2015), Los canónigos del Cabildo de la Catedral de Almería (1505-1936), tesis doctoral inédita, Almería.

Fernández Gracia, Ricardo (1999), "La sacristía de la catedral de Pamplona. Uso y función. Los ornamentos", Príncipe de Viana, 60, pp. 349-382.

Ferrer Flórez, Miquel (2001), "Culte a Ramon Llull: discòrdies i controvèrsies", Studia Lulliana, 41, pp. 65-89.

García Pérez, Francisco José (2014a), "El Cabildo catedralicio de Mallorca (17001750). Estudio de una élite de poder durante el siglo XVIII", Tiempos Modernos, 8, $\mathrm{n}^{\circ} 29$. [Versión electrónica].

García Pérez, Francisco José (2014b), "La persecución del lulismo en la Catedral de Mallorca durante el episcopado de Juan Díaz de la Guerra (1772-1777)", Hispania Sacra, vol. 66, Extra 2, pp. 397-419.

García Pérez, Francisco José (2017a), "El cabildo de Mallorca y el vicario general sede vacante durante el Setecientos. Disputas y ámbitos de poder", Revista de historia moderna: Anales de la Universidad de Alicante, 35, pp. 497-529.

García Pérez, Francisco José (2017b), "Los canónigos de la Catedral de Mallorca durante el siglo XVII", Cauriensia, vol. XII, pp. 407-442.

García Pérez, Francisco José (2017c), "El Seminario conciliar de Mallorca durante el Setecientos. Entre el florecimiento y la decadencia", Cuadernos de Historia Moderna, 42/1, pp. 221-238.

García Pérez, Francisco José (2017d), La cruzada antilulista, Palma.

Iglesias Ortega, Arturo (2016), "Nepotismo y patronazgo eclesiástico en la Galicia Moderna: el Cabildo catedralicio de Santiago de Compostela", Hispania Sacra, 137, pp. 259-280.

Irigoyen López, Antonio (2001), Entre el cielo y la tierra, entre la familia y la institución: el cabildo de la catedral de Murcia en el siglo XVII, Murcia.

Latorre Ciria, José Manuel (2009), "Perfiles de un grupo eclesiástico: los canónigos aragoneses del último tercio del siglo XVIII", Hispania Sacra, 61, pp. 545-569.

López, Roberto J. (2010), “El Cabildo y los canónigos de la Catedral de Oviedo en la Edad Moderna. Un repaso por la historiografía reciente y una propuesta de investigación", Semata, Ciencias Sociais e Humanidades, 22, pp. 131-155.

Martí Gelabert, Francisco (2004), Carlos III y la política religiosa, Madrid.

Martín Hernández, Francisco (1984), "La formación del clero en los siglos XVII y XVIII”, en García-Villoslada, Ricardo (dir.). Historia de la Iglesia en España, Madrid, pp. 524-587. 
Mateu Mairata, Gabriel (1985), Obispos de Mallorca, Palma.

Montaner, Pere de (1989), "Senyor a Mallorca: un concepte heterogeni”, Estudis Baleàrics, 34, pp. 5-35.

Montaner, Pere de (1990), Una conspiración filipista. Mallorca, 1711, Palma.

Morgado García, Arturo (1997), "El alto clero gaditano durante el Antiguo Régimen (1600-1833)", Studia Histórica, Historia Moderna, 16, pp. 223-256.

Morgado García, Arturo (2000), "Vida de canónigo. Percepción, origen y estatus de vida del alto clero durante el Antiguo Régimen", en Aranda Pérez, Francisco José (coord.). Sociedad y élites eclesiásticas en la España Moderna, Cuenca, pp. 77-100.

Planas Rosselló, Antonio y Ramis Barceló, Rafael (2011), La facultad de Leyes y Cánones de la Universidad Luliana y Literaria de Mallorca, Palma.

Ramis Barceló, Rafael (2014), "Los colegiales del Pontificio Colegio de la Sapiencia de Mallorca durante el siglo XVIII", Obradoiro de Historia Moderna, 23, pp. 238-257.

Ramis Barceló, Rafael (2015a), “Los graduados en leyes y cánones en la Universidad de Barcelona durante el siglo XVI", Anuario de Historia del Derecho Español, 85, pp. 475-496.

Ramis Barceló, Rafael (2015b), "Teólogos hispanos en la Universidad de Pisa durante los siglos XVI y XVII”, Carthaginensia, 21, pp. 663-684.

Ramis Barceló, Rafael (2017), Doctores hispanos en Leyes y Cánones por la Universidad de La Sapienza de Roma (1549-1774), Madrid.

Ramis de Ayreflor Sureda, José (1947), El canónigo don Antonio Figuera (16691747), Palma.

Ramis de Ayreflor Sureda, José (1944-46), "El canónigo don Antonio Figuera (1669-1747)", Bolletí de la Societat Arqueolòica Lul·liana, 29, pp. 734-736.

Rey Castelao, Ofelia (1998), "La Iglesia gallega en tiempos de Felipe II: la aplicación del Concilio de Trento", en José Martínez Millán (ed.), Felipe II (15271598): Europa y la Monarquía católica. Vol. 3, Madrid, pp. 341-364.

Rosselló Lliteras, Joan (1978), "Estratificación social del clero de Mallorca”, Bolletí de la Societat Arqueològica Lul-liana, 36, pp. 189-208

Terrassa, Guillem (1883), Anales del Reino de Mallorca. Siglo XVIII, desde el año 1700 hasta el de 1770, Palma.

Vidal y de Barnola, Luis Alfonso (1993), "Títols nobiliaris de Mallorca”, Paratge 3-4, pp. 49-56.

Xamena, Pere y Riera, Francesc (1986), Història de l'Església de Mallorca, Palma. 